\title{
Historia del turismo en Ibiza: Aplicación del Ciclo de Vida del Destino Turístico en un destino maduro del Mediterráneo
}

\author{
José Ramón Cardona* Antoni Serra Cantallops**
}

Universitat de les Illes Balears (España)

\begin{abstract}
Resumen: Ibiza es una isla del Mediterráneo caracterizada por un desarrollo económico basado en el turismo de sol y playa. El turismo inició su desarrollo en Ibiza en el primer tercio del siglo XX, pero no alcanzó elevadas cuotas de crecimiento hasta los años sesenta y setenta. En la actualidad es un destino maduro con una gran imagen de marca. El objetivo del presente trabajo es exponer la evolución del turismo en Ibiza, ayudándonos del modelo de Ciclo de Vida del Destino Turístico. Ibiza parece seguir las pautas del modelo descrito por de Butler (1980) con gran exactitud y sólo se difumina este hecho por los impactos negativos externos (guerras, crisis, etc.), causando una demora en el proceso. Para mejorar el modelo de Ciclo de Vida se propone introducir un Fase Preturística, medir la demanda en pernoctaciones y definir la región estudiada como el producto comercializado.
\end{abstract}

Palabras Clave: Ciclo de Vida del Destino Turístico, Ibiza, desarrollo turístico, estancamiento, turismo de sol y playa.

History of tourism in Ibiza: Application of Tourism Destination Life Cycle in mature Mediterranean destination.

Abstract: Ibiza is a Mediterranean island whose economic development is highly dependent on sun and beach tourism. Tourism in Ibiza began its development in the first third of the 20th century but experienced its highest growth rates along the sixties and seventies. Nowadays, Ibiza is a mature tourism destination with a strong brand image. The aim of this paper is to analyze the evolution of tourism in Ibiza, taking the Tourism Destination Life Cycle model as a basis. Ibiza seems to follow the model described by Butler (1980) with high accuracy and only some external negative impacts (wars, crises, etc.) seem to cause a certain delay in the different life cycle phases. To improve the Life Cycle model is proposed to introduce a Pretourist Phase, measure the demand in overnight stays and define the region studied as the marketed product.

Key Words: Tourism Destination Life Cycle, Ibiza, tourism development, stagnation, sun and beach tourism.

\section{Introducción}

Ibiza es una isla del mediterráneo occidental caracterizada por su fuerte dependencia económica del turismo, debido a que permitió abandonar la situación de pobreza anterior. Danielle Rozenberg resaltaba la importancia del turismo en la historia de Ibiza y comentaba que "los mismos ibicencos, para diferenciar el tiempo hablan de antes del turismo y de ahora. Saben que son dos épocas, dos eras muy distintas" (Planells, 1986: 33). El interés de estudiar el caso de Ibiza se fundamenta en dos elementos: es un destino maduro, con un siglo de historia turística y una importante imagen internacional, y poseía peculiaridades en su cultura tradicional (hábitat y arquitectu-

\footnotetext{
Doctorando. Profesor Asociado de Comercialización e Investigación de Mercados. Departament d'Economia de l'Empresa; E-mail: jose.ramon@uib.es

** Profesor Titular de Comercialización e Investigación de Mercados. Departament d'Economia de l'Empresa; E-mail: antoni.serra@uib.es
} 
ra rural, etc.) causadas, posiblemente, por una evolución histórica distinta a otras regiones del Mediterráneo y que favorecieron la creación de una imagen de destino de libertad y vida alternativa. La combinación de estos dos elementos hace de Ibiza un ejemplo difícilmente comparable. El objetivo que pretendemos es el de exponer la historia del turismo en Ibiza y comprobar hasta qué punto se adapta a la teoría del Ciclo de Vida del Destino Turístico (CVDT) desarrollada por Butler (1980).

El CVDT toma como hipótesis que el destino turístico, entendido como un conjunto de productos turísticos, experimenta un ciclo vital similar al Ciclo de Vida de los productos de consumo (Serra, 2002), pasando por diversas fases. El trabajo de Butler (1980) es considerado la primera descripción detallada del CVDT. Desde entonces se han realizado trabajos encaminados a aplicar este modelo en diversos destinos turísticos (Ioannides, 1992; Meyer-Arendt, 1985; Prideaux, 1996, 2000; Priestley y Mundet, 1998; Wilkinson, 1987), pero también críticas o revisiones del mismo (Baum, 1998; Benedetto y Bojanic, 1993; Cooper y Jackson, 1989; Cooper, 1990; Debbage, 1990; Fernando et al., 2011: 241-242; Getz, 1992; Haywood, 1986; Hovinen, 1982; Weaver, 1990).

Entre los diferentes estudios de caso en que parece confirmarse el modelo de Butler (1980) podemos encontrar los trabajos realizados por Oglethorpe (1984) en Malta, Meyer-Arendt (1985) en Grand Isle (Luisiana), Richardson (1986) en Galveston, Wilkinson (1987) en diversas islas del Caribe (Aruba, Santa Lucía, Antigua y Las Islas Vírgenes Americanas), Debbage (1990) en Paradise Island (Bahamas), Foster y Murphy (1991) en Parksville y Qualicum, Morgan (1991) en Mallorca, Ioannides (1992) en Chipre, Smith (1992) en Coney Island, Akama (1999) en Kenya, y Pulina, Dettori y Paba (2006) en los agroturismos de Cerdeña. Aunque a veces coinciden de una forma más perfecta con el modelo, en otros casos es sólo aproximado. Spey Valley (Escocia) puede considerarse un destino turístico situado en la fase de madurez, en la cual coexisten elementos de las fases de crecimiento, declive y rejuvenecimiento (Getz, 1994). En Torbay (Reino Unido) fue difícil determinar las fases del ciclo de vida del destino turístico a causa de que el destino se componía de tres zonas (Torquay, Paignton y Brixham) con evoluciones diferenciadas. Aún así fue posible determinar las distintas fases del destino de una forma aproximada (Agarwal, 1997).

Estudios realizados en Lancaster County (Pennsylvania) por Hovinen $(1982,2002)$ encontraron que el modelo propuesto por Butler (1980) no es del todo adecuado para describir la evolución de la industria, sobre todo en las fases finales del modelo, proponiendo una fase de "madurez" que englobe las de consolidación y estancamiento. Un estudio realizado en Port Stephens (Baker, 1983) encontró bastantes diferencias con el modelo original de Butler (1980) en las características de las fases. En un estudio realizado en la Isla de Man (Cooper y Jackson, 1989) encontraron que la evolución del destino no coincidía con la curva y las fases del modelo. En Gran Caimán (Weaver, 1990) se encontró una gran desviación respecto al modelo, principalmente en lo referente al control local del sector. También en un estudio de las Cataratas del Niágara (Getz, 1992) se encontraron importantes puntos de divergencia con el modelo.

Algunas de las críticas al modelo hacen referencia a la falta de operatividad (Haywood, 1986), a algunos elementos del modelo (Hovinen, 1982), a su capacidad para representar la realidad (Getz, 1992) y a que es descriptivo, no predictivo (Cirer, 2009; Cooper, 1990; Russell y Faulkner, 2004). Cirer (2009: 309) considera que el modelo de ciclo de vida es bueno aplicado a los destinos turísticos antiguos. Papatheodorou (2004) considera que la evolución no es lineal, pueden producirse cambios abruptos, largos periodos de calma aparente e interrupciones largas y drásticas seguidas de recuperaciones (Cirer, 2009: 310).

Lo más complejo de la aplicación del modelo es la cantidad de factores internos y externos que pueden alterar la evolución del destino turístico. Factores internos de la dinámica del destino turístico (planificadores turísticos y gestores de empresas) son importantes (Cooper y Jackson, 1989), pero también hay factores externos como es el peso de las empresas multinacionales (Bianchi, 1994; Debbage, 1990) o la interacción con grupos de interés o instituciones estatales (Ioannides, 1992). Además, la forma de la curva varía dependiendo de factores de oferta y factores de demanda como pueden ser cambios en la tipología de los clientes (Cooper, 1990). La literatura y casuística existente sobre el modelo del CVDT ha sido recientemente revisada y comentada por Butler (2006a, 2006b, 2012).

Muchos destinos costeros europeos han entrado en la fase de madurez o de post-madurez en las dos últimas décadas (Agarwal, 2002). Estos destinos turísticos adquirieron sus características en los años sesenta y setenta (Gale, 2005), y se orientaron hacia el turismo de masas con una oferta de sol y playa, un producto muy estandarizado y fuerte estacionalidad (Sedmak y Milhalic, 2008). Los primeros destinos en desarrollarse, como es el caso de la Isla de Man (Cooper y Jackson, 1989), se caracterizan por el hecho de que ya han pasado por todas o casi todas las fases del ciclo de vida. 


\section{Gráfico 1: Evolución Turística en Ibiza.}

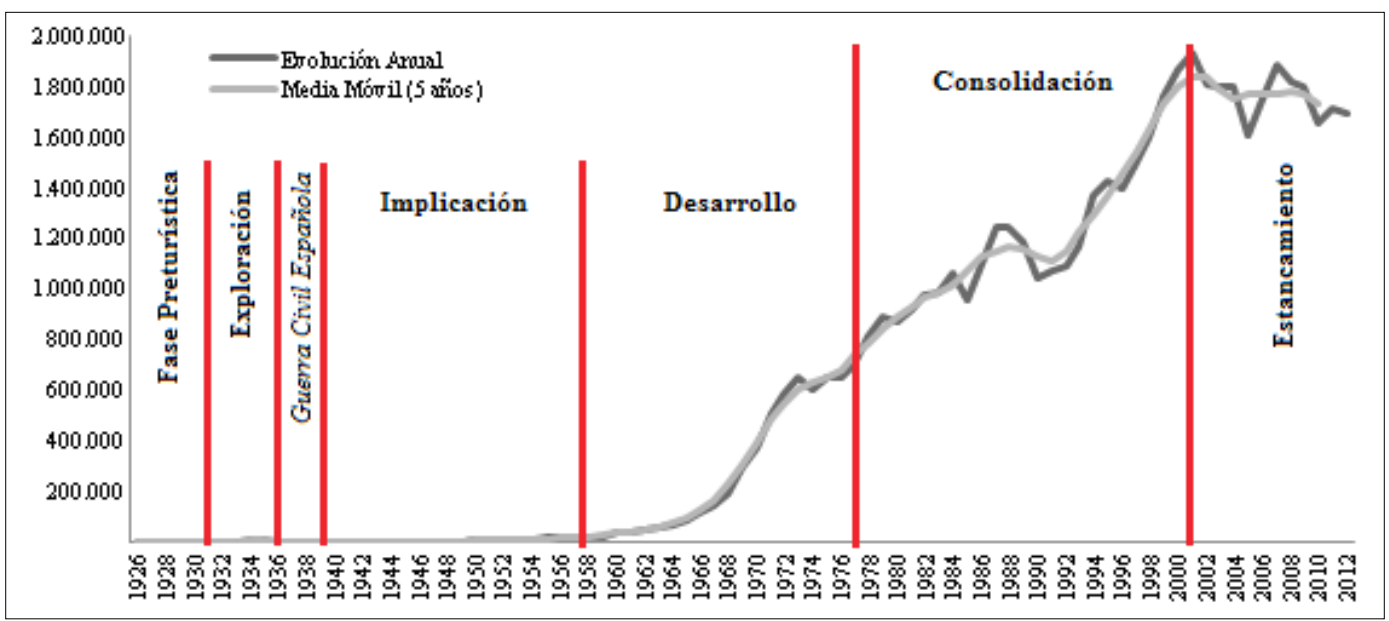

Fuente: Ramón (2001), Cirer (2000), Ibestat, Observatorio de Turismo y elaboración propia.

Otros, como Ibiza, se encuentran entrando en la fase de estancamiento.

En este trabajo se realiza una descripción de las fases del CVDT por las que ha pasado Ibiza (Exploración, Implicación, Desarrollo, Consolidación y Estancamiento) mediante las fuentes historiográficas disponibles. Para la mejor comprensión de la evolución e imagen turística se ha añadido un apartado de análisis de la sociedad previa al desarrollo turístico, denominado Fase Preturística y no existente en el modelo de CVDT. Esta nueva fase no muestra cifras de oferta o demanda turística pero ayuda a comprender el potencial turístico de la región, siendo una introducción o "momento cero" previo a la descripción de las fases del modelo tradicional.

El objetivo del trabajo es una mejor comprensión de la evolución histórica de Ibiza como destino turístico y las causas de su evolución e imagen turística. Se estructura en apartados que corresponden con las fases mencionadas (Gráfico 1), finalizando con un apartado de conclusiones que propone algunas indicaciones para una mejor aplicación del modelo de CVDT a la descripción de casos concretos, algunos ya mencionados (Butler, 2012) y otros no (fase preturística), y que este estudio ha inducido a aplicar.

\section{Fase Preturística: Los primeros visitantes (antes de 1931)}

Esta es la época que podríamos denominar la Prehistoria del turismo en Ibiza, es decir el periodo en que la industria turística era imperceptible. Este periodo llegaría hasta 1930 y se caracteriza por la insistencia de la prensa en destacar la necesidad de potenciar la industria turística (Ramón, 2001: 9). Durante esta etapa, la economía de la isla se basaba en los productos agrícolas, ganaderos y forestales para la exportación y para consumo interno de la isla. En el sector secundario, Ibiza se caracteriza por una baja industrialización (el sector se reduce a los artesanos). El sector servicios vive una leve tendencia hacia el aumento, pero siempre es muy residual (Cirer, 1998, 2002, 2004; Ramón, 2001).

Antes de 1909 no hay menciones a la presencia de visitantes que puedan considerarse turistas y no hay documentos escritos que muestren la existencia de debate sobre el turismo. En esta fase los escasísimos visitantes que llegan a la isla son científicos, escritores, pintores, algún periodista, y aventureros que llegan con la finalidad de explorar sociedades tradicionales. Las personas llegadas en el siglo XIX fueron los primeros en dar a conocer la isla (Planells, 1984: 262). Hasta bien entrado el siglo XX, Ibiza era totalmente desconocida como posible destino vacacional y no se alejaba en exceso de las descripciones dadas por los visitantes. Vuiller menciona que "las Pitiüsas [Ibiza y Formentera] son menos conocidas, aún, que las Baleares y de ellas se cuentan cosas terribles" (Vuiller, 2000: 15). Además, Ibiza se caracterizaba por una enorme falta de infraestructuras, un hábitat rural disperso (casas aisladas en el campo y sin tradición de pueblos o aglomeraciones urbanas más allá de Ibiza ciudad), arquitectura rural peculiar (modular y con reminiscencias arcaicas), mínima estratificación 
social, hospitalidad con el extraño, etc. (Fajarnés, 1995). Todo ello facilitó el atractivo del destino y la imagen de libertad y tolerancia.

Los primeros visitantes sirvieron de detonante para que a principios de siglo se produjera un debate en la prensa local sobre la necesidad de fomentar un sector que se preveía motor de desarrollo de la isla, la cual se encontraba en una situación pésima (pobreza, emigración, analfabetismo, alta criminalidad). En este contexto un negocio fácil como aparentemente podía ser el turismo representaba una auténtica esperanza de progreso en todos los órdenes, aunque especialmente en el económico. De ahí la insistencia con que se reclamó, sobre todo desde los periódicos de la época, la creación de hoteles, líneas marítimas, carreteras y actividades de promoción turística (Ramón, 2001: 13-15). Por tanto, el estado de la economía local fue el principal motor que impulso el interés de los residentes en la nueva actividad (Allen, Hafer, Long y Perdue, 1993; Lankford, 1994; Perdue, Long y Allen, 1990).

El primer indicio documental de un interés por desarrollar una industria turística lo encontramos en la aparición de la guía "Ibiza, Guía del Turista" de Arturo Pérez-Cabrero, editada en Barcelona en 1909 y con información bastante completa de los atractivos que ofrecía la isla. En esta época los valores arqueológicos, históricos y paisajísticos constituían el principal reclamo turístico (Ramón, 2001: 12-13).

\section{Fase de Exploración: Orígenes del turismo en Ibiza (1931-1936)}

Los orígenes del turismo en Ibiza se pueden considerar situados en el periodo de 1931 a 1936 (Ramón, 2001: 9). La década de 1930 fue decisiva para la industria turística y puede afirmarse que fue en estos años cuando surgieron las primeras infraestructuras hoteleras propiamente dichas y cuando el turismo nació como tal. La creación del Fomento del Turismo, el aumento de la afluencia turística, a través de yates y cruceros, y la inauguración de importantes hoteles en Ibiza ciudad, Sant Antoni y Santa Eulària constituyeron un conjunto de circunstancias que dieron el necesario empuje inaugural a la nueva industria. Los turistas de esta época encajan en el perfil de los alocéntricos descritos por Plog (1974), sin una nacionalidad predominante y en cifras no superiores a los 5.500 turistas anuales (Ramón, 2001).

En los años treinta, la isla de Ibiza llega a contar con varios hoteles y fondas, con unas 473 plazas en total (Méndez, 2001). Los empresarios que impulsaron el sector en los años treinta eran de tres tipos (Cirer, 2004: 144): personas que ya se encontraban vinculadas al mundo de la hospedería, propietarios rurales enriquecidos con la modernización del campo ibicenco y con la comercialización de sus productos, y extranjeros que vienen como turistas, observan la posibilidad de montar un negocio para permanecer en la isla y no la desaprovechan (Ramón, 2001: 42).

Desde hace dos siglos muchos "espíritus atormentados" han "emigrado al Sur en busca de la isla, donde los perfiles fronterizos están bien delimitados y la utopía nace diáfana" (Planells, 1986: 7). En este migrar del norte (civilizado, frío y ordenado) hacia el sur (arcaico, cálido y caótico), el Mediterráneo y, en especial, sus islas han tenido un papel fundamental e Ibiza era uno más de estos lugares (Planells, 1986: 10; Planells, 2002: 17; Ramón, 2001: 35). La primera oleada de intelectuales, científicos y refugiados llegó a Ibiza en los años treinta (1931-1936). Los artistas Europeos que huían de la convulsa Europa de finales de los años veinte y principios de los años treinta eligieron Ibiza por diversos motivos (Rodríguez, 2003: 16-17), pero tuvo un papel decisivo lo que Xavier Rubert de Ventós denominó "la Mediterránea como mito cultural" (Rubert, 1985). Walter Benjamin, Raoul Hausmann, Erwin Broner (Erwin Heilbronner), Will Faber (Wilhelm Faber), Erwin von Kreibig y Wolfgang Schulze "Wols" son los artistas más representativos que pasaron por Ibiza en los años treinta.

Probablemente, lo que diferencia a Ibiza del resto de destinos en los que se establecieron colonias de artistas e intelectuales es que en Ibiza la presencia de este tipo de visitantes y su relación con la población local fue el principal atractivo de la industria turística, mientras que en otros destinos este aspecto quedó en segundo plano respecto a otros factores como el exotismo (Marruecos, Egipto, etc.), los restos arqueológicos (Grecia, etc.) o el paisaje natural (Mallorca, Menorca, etc.).

En 1936, la situación política y económica produce una parálisis en los viajes de placer y un clima de gran tensión recorre toda Europa. El 18 de julio estalló la Guerra Civil española, pero en Ibiza los hechos más sangrientos no se producirían hasta septiembre, aunque nadie era ajeno a la gravedad de la situación.

\section{Fase de Implicación: El turismo renace (1939-1957)}

En esta fase se produce la recuperación de los avances realizados en los años treinta y se crea un potente sector turístico que a finales de los años cincuenta ya no sólo es importante para la economía local sino que se está convirtiendo en el 
principal sector económico (Cirer, 2004: 239). La Fase de Implicación se puede subdividir según la tendencia del crecimiento en dos partes. De 1939 a 1950 el desarrollo turístico es muy lento (o está estancado) debido a los efectos de la Guerra Civil Española, la Segunda Guerra Mundial y los primeros, y más duros, años de posguerra, bloqueo internacional y política autárquica. Estos elementos frenaron el desarrollo turístico durante los años cuarenta pero generaron una fuerte implicación de gran parte de la población local que dio sus frutos en los años cincuenta (Ramón, 2001). A partir de 1950 el sector turístico recupera y continúa por la senda que había iniciado antes de la Guerra Civil: aumenta la oferta de plazas, regresan los artistas e intelectuales y aparecen los beatniks (miembros de la contracultura surgida en los años 1950 en Estados Unidos, antecesora de los hippies, y caracterizada por el anticapitalista, el antiautoritaria, el individualista y la admiración por los autores de la generación Beat). Los turistas de esta época poseen el mismo perfil de la fase anterior pero predominan los franceses.

\section{La Posguerra}

La Guerra Civil Española y la II Guerra Mundial causaron la desaparición del turismo existente hasta la fecha. Años de trabajo para levantar el sector se habían desmoronado y era preciso volver a empezar. La situación hotelera en la isla era caótica. Desde 1936 y hasta el final de la Segunda Guerra Mundial los hoteles de la ciudad estuvieron ocupados militarmente y los de Santa Eulària cerrados, permaneciendo sólo abiertos los de Sant Antoni. Los únicos hospedajes que funcionaban en la ciudad eran Fonda la Marina y Fonda del Comercio, establecimientos de pequeñísima capacidad y larga tradición como hospedería (Cirer, 2004: 172, 183-184; Planells, 1984: 266; Ramón, 2001: 70).

En junio de 1946, se reinauguró el antiguo Gran Hotel con el nombre de Hotel Ibiza, ya que la nueva ley turística reservaba el apelativo de "Gran" a los hoteles de lujo. Sus nuevos responsables lograron que la ciudad contase con un hotel de calidad, pero económicamente fue un desastre (Cirer, 2004: 183-185; Ramón, 2001: 71-73). El 21 de septiembre de 1947 se produjo el restablecimiento de la línea Ibiza-Barcelona inaugurado en 1909 e interrumpido en 1936 por la Guerra Civil. Este servicio era importantísimo, no sólo para el servició de los residentes, sino para incrementar la incipiente corriente de veraneantes. Pero las comunicaciones seguían siendo escasas y los problemas de suministros e infraestructuras limitaban el futuro del turismo (Cirer, 2004: 211; Ramón, 2001: 74; Torres, 1961).
A partir de 1949 aparecieron algunas normas que facilitaron la actividad turística (Cirer, 2004: 189).

En 1950 las camas ofertadas eran 481, mientras que en 1935 eran 473. Habían reabierto algunos establecimientos, otros no volvieron a abrir y se abrieron algunas pensiones nuevas, el resultado es que se estaba en 1950 en el punto en que se había quedado el desarrollo turístico antes de la Guerra Civil (Cirer, 2004: 216).

La década de los cincuenta: empieza el despegue del sectorEl levantamiento del embargo de la ONU a España, en 1950, propició un aumento en el número de viajeros llegados a la isla. En 1955 se establecieron servicios extraordinarios de trasporte marítimo en los meses de julio, agosto y septiembre (Cirer, 2004: 211). Este hecho permitió aumentar de forma significativa las llegadas de turistas, principalmente españoles. El aeropuerto de Es Codolar fue aeródromo militar hasta el 1 de junio de 1958, cuando abrió al tráfico comercial (Soriano, 1996) pero funcionando de forma muy precaria. A partir de 1964 el aeropuerto de Ibiza pudo empezar a operar con normalidad, aunque los vuelos internacionales no pudieron aterrizar en el aeropuerto hasta que se habilitó la aduana en 1966 y el aeropuerto adquirió la categoría de internacional (Cirer, 2004: 213). Con la apertura del aeropuerto al tráfico internacional, el turismo de masas contratado por turoperadores comenzó a llegar y el turismo predominante pasó a ser el inglés.

Entre los turistas extranjeros, la nacionalidad dominante en un primer momento fue la francesa. Hasta 1957 los franceses eran más del 25\% del total de turistas, pero después fueron perdiendo presencia en favor de los ingleses (Cirer, 2004: 210). Los primeros datos fidedignos de las entradas de turistas son del año 1954. De los años anteriores no hay más que algún testimonio aislado y datos muy indirectos (Cirer, 2004: 209). A partir de 1955, con el establecimiento de las líneas marítimas de verano, y de 1958, con la apertura del aeropuerto, se produce una aceleración en el crecimiento del número de llegadas, alcanzando en 1960 los 24.400 turistas alojados en hoteles. A lo que hay que añadir los turistas que alquilan habitaciones o casas y los que tienen una vivienda de su propiedad en la isla.

En 1950 las camas ofertadas eran 481 y, por tanto, se recuperaba el nivel anterior a la Guerra Civil. Entre 1950 y 1955 se produjo un significativo aumento de las plazas ofertadas, doblándose la oferta de alojamiento (1.014 camas). Entre 1955 y 1960 la oferta de plazas turísticas se triplicó, llegando a las 3.357 camas (Cirer, 2004: 216-218; Ramón, 2001: 80). La oferta de los años cincuenta y sesenta se caracterizaba por el predominio de las 
plazas ofertadas en hostales y pensiones (Cirer, 2001).

La zona turística por excelencia era Sant Antoni. Hasta 1960 la bahía de Sant Antoni de Portmany concentraba entre la mitad y dos tercios de las plazas (Cirer, 2001; Cirer, 2004: 216-218) y casi monopolizaba el crecimiento en plazas y en turistas (Buades, 2004: 172). Esto era debido a que la situación era diferente entre Ibiza ciudad y Sant Antoni en lo que a restricciones morales se refiere. El hecho de que en 1936 los guardias destinados en la zona y el Ayuntamiento de Sant Antoni hicieran todo lo posible para que la guerra tuviera el mínimo impacto en Sant Antoni, permitió que sus establecimientos permanecieran abiertos y las normas referentes a la moral pública se relajaran enormemente. Esta diferencia hizo que el liderazgo que había tenido la capital en los años treinta se perdiera en favor de Sant Antoni.

En los años cincuenta se produjo la llegada de la segunda oleada de intelectuales y artistas a la isla, tras la de los años treinta. Esta segunda remesa vino atraída por la difusión que realizaron los visitantes de los años treinta en determinados ambientes culturales. El ambiente bohemio del París de la época fue el principal difusor de Ibiza como destino.

A partir de 1953, la isla recibe de nuevo a muchos de aquellos viajeros que escribían, pintaban, diseñaban, proyectaban $o$, simplemente, observaban y huían de un pasado traumático (Planells, 2002: 37-38) y que van conformando una nueva forma de vida que ya será descaradamente rupturista a finales de los cincuenta (Planells, 2002: 9): Erwin Broker, Alan Schmer, André Kuyten, Bert Schierbeeck, Carlos Dudek, Cliford Irving, Cornelis Bastiaan, David Walsh, Edith Sommer, Erwin Bechtold, Frank El Punto, Hans Laabs, Harry Mulisch, Heinz Trökes, Hugo Claus, Ignacio Aldecoa, Ingeborg, Ivan Spence, Jan Cremer, Jan Gerhard Toonder, Janet Frame, José Fin, Katya Meirowsky, Laurie Lee, Paul Brunswick, Paul Grant, Phil Hoffman, Rafael Azcona, Sioma Baram, Stephen Seley, Vert Schierbeeck, Waldemar Post, etc. Las bondades de la isla que atrajeron a los extranjeros son enumeradas de forma clara:

"Si a esa libertad absoluta para vivir de que se gozaba le sumamos una situación geográfica envidiable, la benignidad del clima, la buenaventura del mar Mediterráneo, las innumerables bellezas naturales de la isla aún vírgenes casi, la conservación de una ciudad antigua intacta y con vida [...], pues añadámosle como propina un coste de vida, una baratura de precios increíble, y comprenderemos facilísimamente que Ibiza se convirtiera en polo de atracción de artistas, bohemios y bon vivants del mundo entero" (de Castro, 2003: 173).
Era paradójico comprobar como muchos artistas que habían vivido la dictadura nazi afirmaban tener libertad en un estado dictatorial como era la España de la época. La única explicación era la desconexión con la sociedad ibicenca y la relajación de la represión en Ibiza (Rodríguez, 2003: 43).

En esta época es cuando llegó un grupo particular de personas, los beatniks, grupo contracultural de la época vinculado a las vanguardias (Cerdà y Rodríguez, 1999: 9-10; Planells, 2002: 14-15). Aunque la importancia numérica y las actividades de los beatniks fueron poco visibles al mezclarse con los artistas e intelectuales, su presencia en la isla desde 1955 hasta bien entrados los sesenta resulto importante para dar a conocer la isla a los miembros del movimiento hippie. La principal diferencia entre los beatniks y los hippies es el extremo individualismo de los primeros frente al espíritu comunitario y tribal de los últimos (Ramón, 2001).

En los años cincuenta, para competir con Mallorca, la industria turística ibicenca orientó la mayor parte de sus esfuerzos en ofrecer un producto diferenciado. Para ello recurrieron a explotar el encanto de Ibiza entre los artistas, beatniks y otros actores provenientes del exterior.

\section{Fase de Desarrollo: El "boom" turístico (1958-1976)}

En los años sesenta y setenta se produce una gran aceleración del crecimiento de la oferta y del número de turistas. En este periodo se producen los fenómenos del movimiento hippie, la aparición del empresariado hotelero contemporáneo y un gran desarrollo urbanístico (Ramón, 2001: 9). El boom de esos años representa sin duda un punto de inflexión en la historia de Ibiza, con sus ventajas y sus inconvenientes. E perfil de los turistas cambia. Los franceses llegados por mar son eclipsados por los británicos llegados en avión y con características más próximas a los psicocéntricos descritos por Plog (1974).

Los cambios que hicieron posible el boom turístico fueron la apertura del aeropuerto de Ibiza en 1958, la aprobación de diversas leyes de ámbito nacional que simplifican los formalismos de entrada en el país en 1959, la devaluación de la moneda española y una cierta apertura de España a capitales exteriores (Rozenberg, 1990: 134-135). Además llegan ayudas para financiar los hoteles desde el gobierno nacional y desde los turoperadores de los países emisores.

A partir de este momento los cambios en la sociedad insular se aceleran. La emigración dejará de ser necesaria y el campo se despoblará de agri- 
cultores con rapidez. El turismo se convierte en la salvación a años de carencias y miserias (Ramón, 2001: 91). Ibiza, con unos diez años de retraso, sigue el ejemplo de Mallorca en su desarrollo turístico: fuertes concentraciones hoteleras al borde del mar, recurso a la financiación extranjera en ausencia de financiación estatal, etc. (Rozenberg, 1990: 136).

Esta fase se puede subdividir según la tendencia del crecimiento del sector en tres partes (Cirer, 2000). Entre 1958 y 1964 se produjo una importante aceleración de las llegadas de turistas y del volumen de plazas turísticas, coincidiendo con la mejora de los transportes que comunican Ibiza con el exterior. Tras las mejoras del transporte marítimo y aéreo, se produjo el boom turístico del periodo 1964-1973. Esta fase se caracteriza por los elevados incrementos anuales tanto en la oferta turística, como en la llegada de visitantes. Finalmente, la crisis del petróleo hace sentir sus efectos y de 1974 a 1976 cambia la tendencia. No hay bajada pero se detiene el crecimiento debido, principalmente, a la incertidumbre de la crisis, aunque los cambios políticos que vivió España en esos años es probable que influyeran (Ramón, 2001: 121-123).

En la prensa de la época se muestra el tópico de Ibiza como una isla caracterizada por el azul del mar y el cielo, por la luminosidad y el clima soleado, por un paisaje bucólico referenciado al mundo mitológico griego de los poemas épicos de Homero y por la tolerante hospitalidad de su población autóctona. La mayor parte de la prensa europea y nacional publicaban reportajes, abundantemente ilustrados, que representaban a Ibiza como el refugio de los marginales del mundo (Rozenberg, 1990). Desde entonces, los reportajes de la prensa escrita y de los medios audiovisuales, la publicidad e incluso las agencias de viajes y los turoperadores de los países de origen han contribuido enormemente a la perpetuación de la imagen de isla bohemia y festiva a través de los años, llegando hasta el día de hoy.

Los grupos vinculados a la contracultura tienen su máxima presencia mediática con los hippies. Los movimientos contraculturales se inician en los años cuarenta (con los hipsters, antecedente de los beatniks, y con un estilo de vida influenciado por el jazz) y cincuenta (beatniks), alcanzando su apogeo a finales de los años sesenta con los hippies. Entre finales de los sesenta y principios de los setenta se produce la dispersión de los hippies por el mundo, siguiendo una ruta de oeste a este. La ruta empezaba en San Francisco y llegaba a la India pasando por puntos intermedios como París, Ibiza, Creta, Goa o Estambul (Cerdà y Rodríguez, 1999: 13). El periodo 1968-1974 representa la época "clásica" de la contracultura y se ha convertido en el modelo a imitar por los movimientos posteriores.
Es como parte del éxodo de los integrantes de la contracultura como Ibiza se convierten en importante enclave del movimiento hippie.

\section{Década de los sesenta}

La década de los sesenta empezó con carencias en la oferta y el transporte, pero con el paso del tiempo se corrigieron en gran medida. Se establecieron enlaces directos con Barcelona, Valencia, Palma y Alicante y se mejoró el aeropuerto (Cirer, 2004: 211; Ramón, 2001: 92). El crecimiento del número de turistas a causa de las mejoras en las comunicaciones fue exponencial. Si en 1961 el número de visitantes fue de 42.742 , en 1970 se situaría en 361.670. Definitivamente había empezado el boom turístico, dejando atrás las cifras testimoniales y convirtiéndose la industria turística en el negocio que más gente ocupaba (Cerdà y Rodríguez, 1999: 34, 43; Ramón, 2001: 96-97; Rodríguez, 2003: 86).

El aumento en el número de turistas fue acompañado de un aumento en el número de plazas en una proporción similar. En esta época, la mayor cantidad de fondos la aportaron los turoperadores, que anticipaban el dinero necesario para construir el hotel (Buades, 2004: 173; Ramón, 2001: 113-115). Es importante destacar el hecho de que entonces, la gran mayoría de quienes construían hoteles y apartamentos eran ibicencos o empresarios afincados en la isla. La penetración de compañías peninsulares o extranjeras sería posterior, aunque los empresarios insulares han sido siempre los que han dominado el sector.

Durante los sesenta se produjo la convivencia de distintos grupos humanos, y sus culturas: la población autóctona ibicenca, que aún vive del campo en una parte muy importante y empieza a trabajar en el turismo; los trabajadores de la península que vienen para trabajar en el sector turístico y huyen de la pobreza de sus pueblos; los individualistas beatniks que buscaban un lugar tranquilo y "oculto" al mundo moderno, y que están en retirada; los hippies que, envalentonados por las protestas sociales que azotan Europa occidental y Norteamérica, siguen los pasos de los beatniks pero poseen un comportamiento más gregario, $\mathrm{y}$ los turistas, cada vez más numerosos y más monocromáticos en lo que se refiere a nacionalidades.

A finales de los sesenta, Ibiza empieza a ser cara y aburrida para algunos artistas, ya no es un "refugio secreto y calmo" y se convierte en multitudinario punto de paso del movimiento hippie. Los artistas e intelectuales que frecuentaban la isla desde los años cincuenta empiezan a abandonar la isla dejando paso a los hippies, los cuales acapararan la atención de los medios de comunicación de la época hasta que a principios de los setenta se produce su declive, quedando reducidos a un folklorismo más en los ochenta. "El movimiento hippie fue 
estúpido", afirmó años después Carolyn Cassidy: "El movimiento hippie fue una vulgarización a ras de suelo, a la baja, del movimiento beat, pero con más luz, sonido y colorido y, evidentemente, con más repercusión en los medios" (Planells, 2002: 76).

\section{Década de los setenta}

La década de los setenta fue en esencia una continuación de las tendencias de los años sesenta pero con varias peculiaridades: el crecimiento del volumen de oferta y de llegadas de turistas es más lento que en la década previa, se produce el fin del fenómeno hippie, surge la primera oferta de discotecas de la isla como continuación de los pubs y salas de fiestas de los años cincuenta y sesenta, se produce un cambio de régimen político en España, la primera crisis económica desde la posguerra se cierne en la economía, se crean nuevas instituciones para organizar la oferta del sector, y aparecen las primeras voces que piden la limitación del crecimiento del sector.

Los años setenta fueron dominados por los hoteles de dos y tres estrellas, y la distribución de plazas es muy estable con la única salvedad de que Sant Antoni pierde cuota en favor de Sant Josep y Sant Eulària (Cirer, 2001). A diferencia de la década de los sesenta el incremento del número de plazas se moderó, aunque aún había volúmenes importantes de nueva oferta. La comunidad local que había permanecido de espaldas a la comunidad extranjera se vuelca de forma masiva en el nuevo sector como fuente de ingresos. A partir de ese momento el declive final del sector agrícola y ganadero de la isla y el incremento de la llegada de turistas anima a una rápida reconversión de los agricultores y pescadores en empleados del sector turístico. Pero el crecimiento del sector supera a la población nativa y atrae a trabajadores de fuera (Aguiló, Barros, García y Rosselló, 2004: 25), principalmente de la península (Extremadura y Andalucía).

Durante los setenta, la sociedad ibicenca se ve transformada por la gran inmigración que llega para trabajar en la industria turística. Una llegada que, si bien alcanzó cifras más importantes en los setenta, ya se hacía notar de manera ostensible a mediados de los sesenta, buena prueba de ello es la creación de una Oficina de Ayuda a los Inmigrantes (Rodríguez, 2003: 61). Esta llegada de población foránea a las islas provocó cambios en la sociedad muy significativos.

En los setenta desaparecieron los apoyos a las vanguardias artísticas y el volumen de turistas, ya muy importante, junto con el aumento de precios convirtió a bohemios, artistas, intelectuales y miembros de la contracultura en general en una minoría a la vez que reliquia del pasado, sustituidos por los turistas que buscan vivir por unos días la libertad, el clima y las fiestas que aquellos vivían y que los medios de comunicación difundían.

\section{Fase de Consolidación: Reflexiones sobre el turismo (1977-2000)}

La Fase de Consolidación se puede subdividir según la tendencia del crecimiento del sector en tres partes (Cirer, 2000). De 1977 a 1988 se produce una expansión rápida y surgen los primeros movimientos críticos de importancia. De 1989 a 1992 se produce la crisis más fuerte del sector en toda su historia. A partir de 1993 se produjo un crecimiento en el número de turistas más acelerado que en los años ochenta. Es el periodo de mayores cifras de toda la historia y en el año 2000 se alcanza un máximo histórico. Durante esta fase el perfil predominante del turista es el de un británico joven, con características de psicocéntrico (Plog, 1974), afición por las discotecas (principalmente en los ochenta) y clase social baja (principalmente en Sant Antoni) o media.

A pesar de esta división en tres partes, a la hora de comentar la evolución del sector se divide en dos partes: antes de la crisis (años ochenta) y después de la crisis (años noventa). La crisis fue un importante toque de atención para la toma de medidas por parte de empresarios y administraciones. La Comunidad Autónoma de las Islas Baleares asumió las competencias de turismo en noviembre de 1983. El conjunto de legislación que fue aprobada desde la transferencia de competencias ordenó y restringió el crecimiento turístico en gran medida. El efecto sobre la oferta fue que en los años noventa se produjo una mejora cualitativa de la planta hotelera y el crecimiento en número de plazas se redujo al mínimo. Al entrar el siglo XXI la evolución de la oferta se fundamenta en mejoras cualitativas y no cuantitativas.

La década de los ochenta empezó bien pero terminó mal y a finales de la década una gran crisis comenzaba a cernirse sobre la isla, aunque sus efectos más desastrosos no se notarían hasta principios de los noventa. En los ochenta se asistió a una consolidación de la industria, a una mayor eficacia promocional y a un asentamiento del turismo en todos sus términos. En cuanto a la nacionalidad de los turistas, cabe mencionar el predominio de ingleses y alemanes. Este hecho es característico del conjunto de Baleares y crea una fuerte dependencia de la situación económica de estos dos países. Con el boom de las discotecas se incorporó el último elemento de la imagen de Ibiza que aún hoy perdura. 
Si la fase de implicación tuvo como elemento característico la llegada de artistas de todo el mundo y la fase de desarrollo el movimiento hippie, la fase de consolidación posee los nightclubs como signo distintivo. Ya existían establecimientos precursores de las discotecas en la ciudad de Ibiza a finales de los cincuenta, pero las discotecas tal y como las conocemos hoy hicieron acto de presencia a lo largo de los setenta y en los ochenta se produjo un incremento de su número y dimensiones. Pacha, Angel's, Playboy, Amnesia y Ku constituían reclamos turísticos de fama mundial. De entre estas discotecas destacaba Ku como referente y símbolo de la vida nocturna de la isla (Ramón, 2001: 158-159). A principios de los noventa se produjo una reducción de este auge, en parte por los cambios de tendencia y en parte por la crisis turística general.

Las deficiencias del boom de los sesenta y los setenta, la falta de profesionalidad, la ausencia de normativas específicas para el sector y el relajamiento que producían unos beneficios seguros condujeron a una pérdida de calidad. Ello fue el detonante de una serie de problemas posteriores, como los turistas conflictivos, una política de precios a la baja por parte de los turoperadores y una imagen en el exterior que nunca había sido tan mala como lo sería en los ochenta (Ramón, 2001: 141). La proporción de turistas "conflictivos" fue siempre reducida en el conjunto de la isla, pero la capacidad de estos jóvenes para generar escándalo resultó muy importante, con la colaboración de los medios de comunicación británicos y españoles que magnificaron la situación.

La crisis que se produjo a finales de los ochenta y principios de los noventa puede achacarse a un conjunto de diversos factores (Ramón, 2001: 163): los cambios socio-culturales, políticos y económicos que se produjeron en la sociedad, cambios en el tipo de turistas y sus comportamientos, el exceso de oferta de plazas que se produjo a finales de los ochenta, la degradación de la oferta, y todo ello agravado por la adversa situación internacional provocada por la primera guerra del Golfo Pérsico. A ello, nosotros añadiríamos el incremento de la competencia consecuencia del crecimiento de la oferta en destinos turísticos emergentes.

La década de los noventa se caracteriza por la crisis de sus inicios y por el proceso de modernización y reflexión colectiva sobre el futuro de la actividad turística en la isla. Fue precisamente coincidiendo con la crisis cuando comienza a surgir una gran cantidad de normas destinadas a reconvertir los establecimientos para adaptarlos a las nuevas exigencias, y la conciencia medioambiental surgida en los ochenta se empieza a plasmar en medidas concretas (Ramón, 2001: 179). La crisis que azotó la isla entre finales de los ochenta y principios de los noventa fue muy grave y afectó a todos los sectores de la sociedad. Los responsables políticos apuntaron al exceso de oferta de plazas de alojamiento como una de las principales causas locales agravantes de la situación. Además la crisis hizo ver a los responsables de la Administración que era necesario confrontar a los turoperadores y empezar a tomar las riendas del canal de distribución, buscando los clientes por otros medios que no fueran los mayoristas.

A partir de 1994 se produjo una progresiva recuperación de las cifras de afluencia turística. En 1994, el número de llegadas internacionales al aeropuerto de Ibiza volvía a ser similar al registrado en 1987 (1.101.700 en 1987 y 1.189 .100 en 1994), justo antes de la crisis (Ramón, 2001: 201-202). El crecimiento en el número de llegadas fue constante hasta llegar a su apogeo en 2000.

Tras el final de la crisis el crecimiento del número de plazas hoteleras fue muy moderado. Entre 1993 y 2000 el crecimiento acumulado anual de las plazas turísticas no llegó al 1\%. Además el crecimiento se ha concentrado en los establecimientos de gama media-alta. Las nuevas construcciones fueron escasas, pero las remodelaciones y las obras de mejora afectaron a la mayor parte de la planta hotelera, implicando en muchos casos un aumento de categoría del establecimiento (Cirer, 2001).

\section{Fase de Estancamiento: Rediseñar la oferta (después de 2000)}

El máximo de afluencia de turistas que se produjo con el cambio de siglo parece marcar un antes y un después en la tendencia del sector. Antes se producía un crecimiento constante, más o menos intenso según las épocas, que sólo se veía interrumpido por descensos coyunturales debidos a crisis internacionales o problemas en los principales mercados emisores. Después del año 2000 se produce una tendencia caracterizada por oscilaciones entorno a los 1,8 millones de turistas anuales (Gráfico 1), con perfil parecido al de la fase anterior. En los últimos años ha incrementado el total de turistas por efecto de las aerolíneas de bajo coste, pero las pernoctaciones no (Gráfico 2). Se puede hablar de fase de estancamiento por dos motivos, aunque la cercanía del periodo estudiado fuerza a mantener una cierta cautela en las afirmaciones. Primero, la tendencia creciente de épocas anteriores desaparece sin una clara situación de crisis internacional que lo explique. Segundo, las personas vinculadas al sector tienen la percepción de que este estancamiento existe (Fehif, 2005: 13-16). 
Gráfico 2: Turistas y pernoctaciones en Ibiza y Formentera (año base 1997).

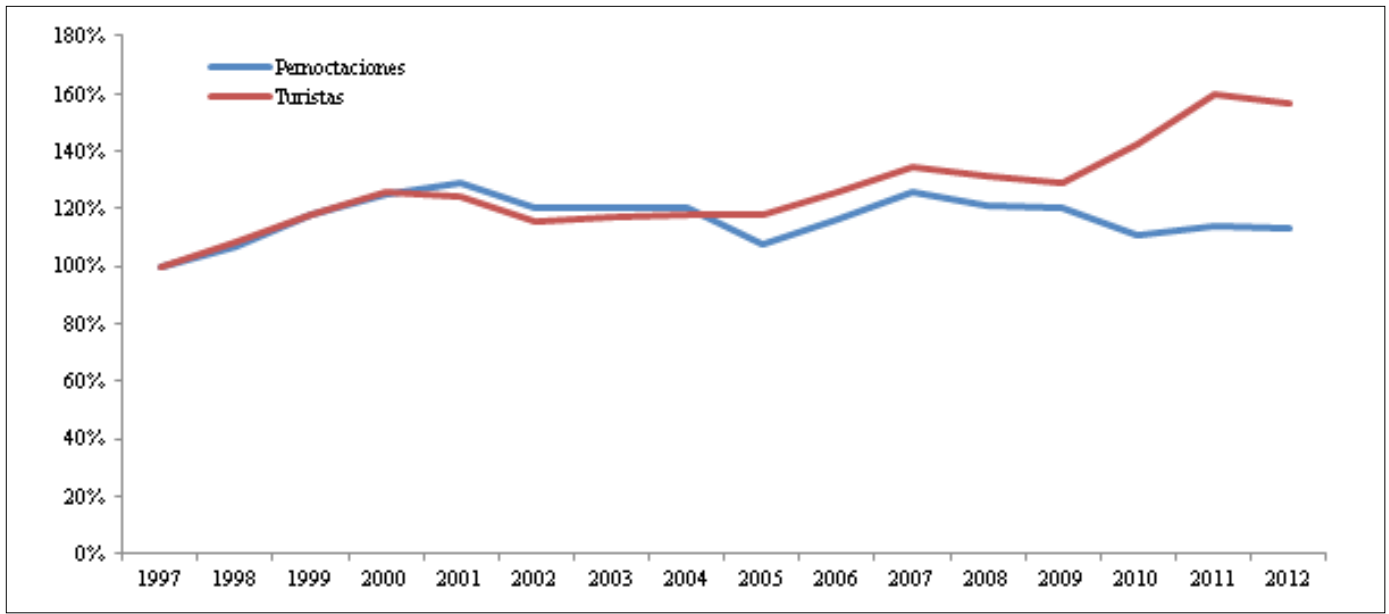

Fuente: Ibestat, Observatorio de Turismo y elaboración propia.

Cuantitativamente la situación se puede definir como "sin novedad", a causa de las pocas variaciones en número de turistas y en número de plazas de alojamiento. Cualitativamente se puede hablar de "esperanza", por los crecientes proyectos que pretenden mejorar las infraestructuras turísticas, principalmente la planta hotelera, y atraer a turistas de mayor poder adquisitivo. Un ejemplo de estas acciones es el Plan de Excelencia Turística para la Platja d'en Bossa propuesto por Palladium Hotel Group (Hosteltur, 11 de febrero de 2013) y que ya se ha empezado a materializar en el Grand Palladium Palace Ibiza Resort \& Spa, el Ushuaïa Ibiza Beach Hotel, The Ushuaïa Tower (Hosteltur, 27 de septiembre de 2012) y el Hard Rock Hotel Ibiza (Diario de Ibiza, 01 de agosto de 2013).

Hay que tener en cuenta que la Ley General Turística establecía que no se podían abrir nuevos establecimientos hoteleros si no eran de 4-5 estrellas y, además, las nuevas plazas debían ser a costa de la amortización de plazas existentes. Según datos del Ibestat en 1999 había un hotel de cinco estrellas (116 plazas) y 12 de cuatro estrellas (3.968 plazas) y en 2012 seis de cinco estrellas (1.035 plazas) y 33 de cuatro estrellas (10.567 plazas). En cambio, según la misma fuente, en 1999 había 542 establecimientos (79.654 plazas) y en 2012 551 establecimientos (79.565 plazas). Mientras que la oferta de mayor categoría a aumentado de forma significativa (por encima del 180\%), la oferta global sólo ha variado el 1,66\% en establecimientos y el $-0,11 \%$ en plazas. Esta mejora cualitativa de la oferta turística (Gráfico 3), combinada con el mantenimiento del volumen de plazas (Gráfico
4) parece indicar que ha calado en el sector la sensación de estancamiento cuantitativo y que ante la amenaza de un declive es necesario buscar un mejor posicionamiento en los mercados turísticos, especialmente atrayendo a los grupos sociales de mayor renta y aumentando los atractivos de la isla.

La promoción turística de la isla se sigue centrando en el ocio nocturno, principalmente, y en el clima, es decir sol y playa. Pero, en los últimos años, Ibiza acapara un gran volumen de noticias referentes a la presencia de famosos y está añadiendo a su imagen previa el glamur. En consecuencia el sector redirige la imagen de la isla hacia una combinación de libertad y vida alternativa, herencia hippie, con una imagen de glamur, sofisticación y lujo. El producto ofrecido no cambia pero se busca orientarlo hacia segmentos de mayor poder adquisitivo.

Las cifras de turistas para el global de Baleares tienen una tendencia que induce a pensar que la situación de estancamiento no es algo propio de Ibiza sino que se produce en todo el archipiélago, según datos del Ibestat y el Observatorio de Turismo de la Caib. Pero es necesario descartar una tendencia general comparando con otras regiones de España. En el Cuadro 1 vemos que Baleares tiene un crecimiento casi nulo y muy inferior al de otras regiones. El resultado es un peso decreciente sobre el total nacional, pasando del $20,51 \%$ en 2001 al 17,52\% en 2008. Ello hace pensar que los resultados de Baleares son debidos a elementos internos y no a la evolución general del sector o la economía. 
Gráfico 3: Plazas en hoteles de cuatro y cinco estrellas en la isla de Ibiza.

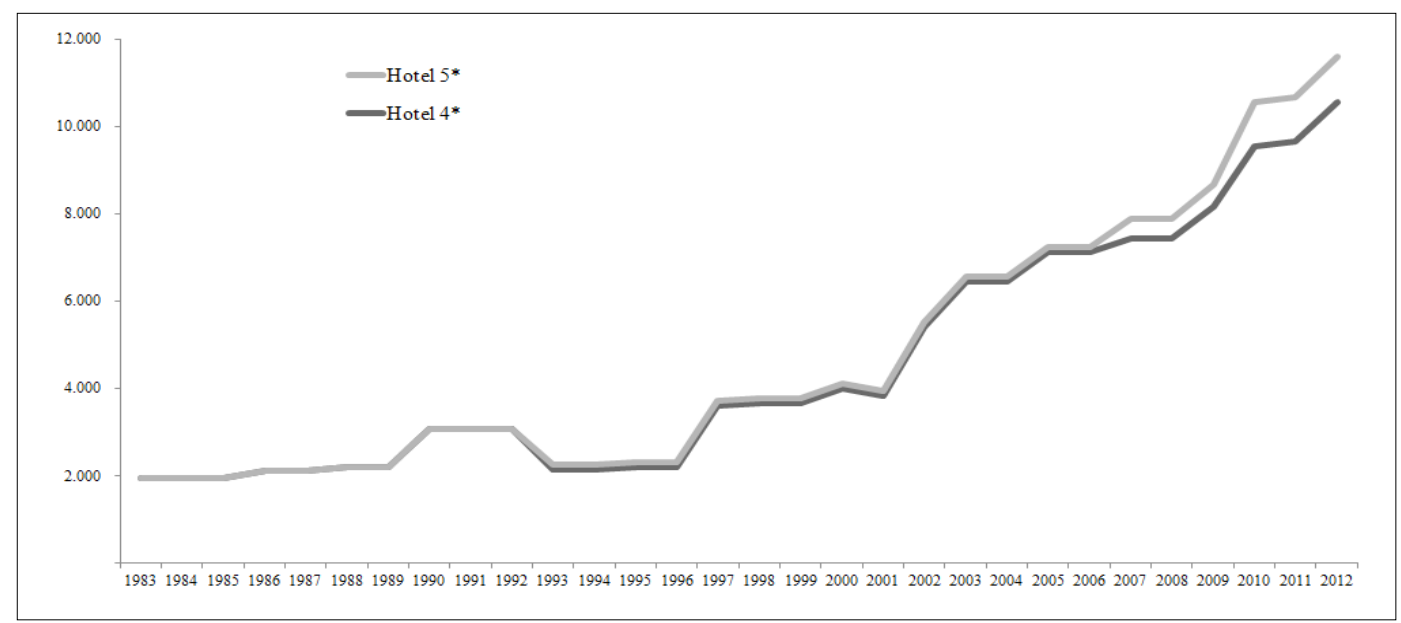

Fuente: Ibestat

Gráfico 4: Plazas en alojamientos turísticos en la isla de Ibiza.

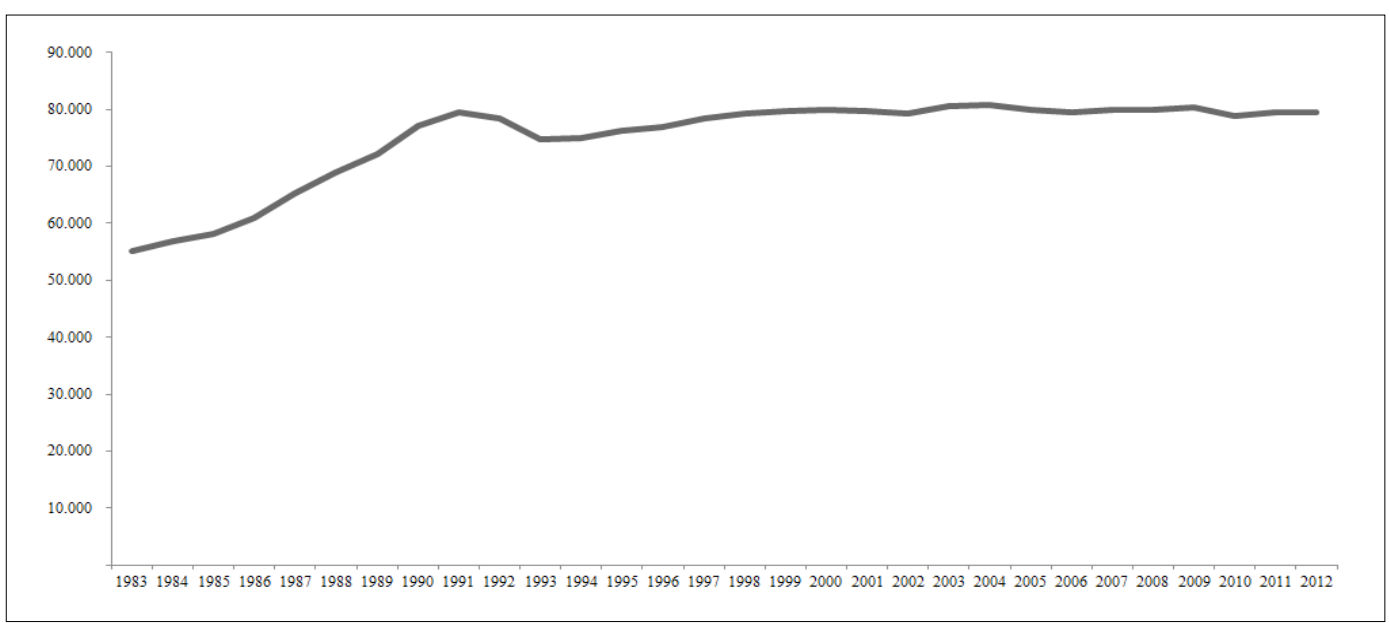

Fuente: Ibestat

\section{Conclusiones}

Ibiza parece seguir las pautas del modelo expuesto por Butler (1980) con gran exactitud y sólo se difumina este hecho por los impactos negativos externos que padece (Guerra Civil Española, II Guerra Mundial, embargo internacional, crisis económicas internacionales, etc.), causando una demora en el proceso. Las fases detectadas en Ibiza son muy parecidas a las que se observan en Grand Isle (Meyer-Arendt, 1985) con ligeros matices, como el efecto de los huracanes en Grand Isle, el desarrollo cronológicamente posterior de Ibiza (en gran parte por las dificultades de acceso a Ibiza desde grandes ciudades cercanas), y que en Grand Isle llegaron primero turistas con alto nivel de renta y después intelectuales (hecho típico en los destinos turísticos desarrollados primero) mientras que en Ibiza los intelectuales fueron la primera oleada de turistas (elemento peculiar de Ibiza y que se ha dado en algunos otros destinos de desarrollo simultaneo o posterior). 


\section{Cuadro 1: Variación en el número de turistas recibidos en España.}

\begin{tabular}{|c|c|c|c|}
\hline & $\mathbf{2 0 0 1}$ & $\mathbf{2 0 0 8}$ & variación \\
\hline Murcia & 398.012 & 790.210 & $98,54 \%$ \\
\hline La Rioja & 33.141 & 63.634 & $92,01 \%$ \\
\hline Aragón & 237.917 & 434.825 & $82,76 \%$ \\
\hline Extremadura & 132.006 & 229.569 & $73,91 \%$ \\
\hline Madrid & 2.967 .935 & 4.615 .616 & $55,52 \%$ \\
\hline Cataluña & 9.683 .337 & 14.344 .333 & $48,13 \%$ \\
\hline Asturias & 126.661 & 181.493 & $43,29 \%$ \\
\hline Castilla - La Mancha & 134.926 & 187.039 & $38,62 \%$ \\
\hline Cantabria & 234.268 & 320.277 & $36,71 \%$ \\
\hline Galicia & 703.367 & 932.870 & $32,63 \%$ \\
\hline Comunitat Valenciana & 4.388 .403 & 5.713 .312 & $30,19 \%$ \\
\hline Total España & $\mathbf{4 8 . 5 6 5 . 3 4 4}$ & $\mathbf{5 7 . 1 9 2 . 0 1 3}$ & $\mathbf{1 7 , 7 6 \%}$ \\
\hline Castilla y León & 864.796 & 999.334 & $15,56 \%$ \\
\hline Navarra & 162.802 & 188.124 & $15,55 \%$ \\
\hline País Vasco & 735.370 & 838.751 & $14,06 \%$ \\
\hline Andalucía & 7.591 .511 & 7.975 .202 & $5,05 \%$ \\
\hline Illes Balears & $\mathbf{9 . 9 6 1 . 9 4 7}$ & $\mathbf{1 0 . 0 2 0 . 7 8 2}$ & $\mathbf{0 , 5 9 \%}$ \\
\hline Canarias & 10.208 .945 & 9.356 .641 & $-8,35 \%$ \\
\hline
\end{tabular}

Fuente: INE

Probablemente, uno de los aspectos más distintivos del caso de Ibiza es que determinadas tipologías de visitantes, que se establecieron en las fases de exploración e implicación (artistas, intelectuales, hippies...), y su forma de vida bohemia e interrelación con la población local, acabaron convirtiéndose en uno de los principales atractivos, a diferencia de otros destinos coetáneos. Posiblemente, este hecho sea debido a las características de la sociedad tradicional de la fase Preturística.

A partir de los estudios de caso revisados y del presente estudio se pueden realizar algunas matizaciones para mejorar el modelo de Ciclo de Vida del Destino Turístico propuesto por Butler (1980):

- Parece lógico introducir una fase Preturística en el modelo para mostrar el punto de partida del destino. Una región con potencial turístico existe $\mathrm{y}$, seguramente, se encuentra habitada mucho antes de que se plantee su desarrollo turístico y conocer esa realidad puede resultar de gran interés para comprender la imagen y evolución posterior. Esta ampliación no aparece en la bibliografía consultada y ayuda a comprender en gran medida lo sucedido en destinos como Ibiza.
- El CVDT se ve alterado por elementos limitadores (guerras, crisis, desastres naturales, etc.) o catalizadores (financiación externa, mejora de infraestructuras, cambios sociales, etc.) del crecimiento turístico, tanto de la oferta como de la demanda. En el caso de Ibiza, la Guerra Civil y las crisis económicas internacionales fueron frenos del crecimiento, y la postguerra (por fomentar la implicación de los residentes), el aeropuerto y la financiación de los turoperadores aceleraron el crecimiento. Estos elementos son mencionados en la literatura (Butler, 2006b, 2012) pero pueden ser tan importantes como para determinar el cambio de fase.

- Las fases de Exploración, Implicación y Desarrollo poseen una evolución determinada por las restricciones al crecimiento de la oferta (falta de financiación, know-how, etc.) y la demanda (mercados emisores, medios de transporte, etc.). La reducción de la tasa de crecimiento que se produce en la fase de Consolidación es debida a que empiezan a alcanzarse los límites de algunas capacidades de carga. Estos límites pueden aumentar con el tiempo (Butler, 2006b) permitiendo el crecimiento durante la fase de 
Consolidación. Cuando las capacidades de carga llegan a su límite detienen el crecimiento y se entra en la fase de Estancamiento. En este momento es fundamental la gestión del destino para evitar el declive (Butler, 2012).

- Estudios como el de Meyer-Arendt (1985) y este sugieren que la entrada en la fase de estancamiento no es suave, sino que se produce un frenazo del crecimiento, seguido de un descenso y una posterior estabilización de las cifras. La estrategia aplicada en Ibiza en esta fase no ha implicado un cambio brusco de producto porque ya tenía un cierto grado de especialización y diferenciación.

- Para la correcta aplicación del CVDT es necesario tener en cuenta que el área estudiada debe ser una región comercializada como un solo producto. Si el área estudiada es mayor a la región normalmente comercializada, probablemente contenga más de un destino turístico y la evolución turística obtenida no coincidirá con el modelo de CVDT por ser la suma de varios CVDT asincrónicos. La correcta definición del destino turístico es mencionada por Butler (2012) y es clave para el correcto uso del modelo.

- Para representar la evolución del destino es necesario analizar diversas variables pero, normalmente, la variable principal es el volumen de turistas. Esta variable es útil si el perfil de los turistas es estable. En el caso de Ibiza se puede suponer esta estabilidad desde 1950 a 2004, dados los datos disponibles (Observatorio de Turismo; Ramón, 2001), y los datos del aeropuerto eran una buena aproximación, pero las aerolíneas de bajo coste han alterado este perfil significativamente, aumentando el volumen de turistas mientras desciende la estancia media. Este cambio se observa en el Gráfico 2 y ha sido corregido en el Grafico 1. Esta posibilidad es mencionada por Butler (2012), pero la importancia de las aerolíneas de bajo coste y los cruceros hacen recomendable sustituir turistas por pernoctaciones, de forma general, para mejorar la representación.

- Cuanto más reciente es el desarrollo del destino más rápido evoluciona por las distintas fases del modelo, debido al aumento de los recursos externos (financiación, know-how, etc.) disponibles.

Por tanto, se propone como mejoras del modelo: introducir una fase Preturística para describir la sociedad tradicional y comprender mejor la posterior evolución; los elementos limitadores o catalizadores del desarrollo turístico pueden marcar los puntos de separación entre fases; la región estudiada debe coincidir con el producto normalmente comercializado; usar como variable principal de medición las pernoctaciones; restricciones, capacidades de carga y recursos disponibles tienen gran relevancia en la determinación de la curva del CVDT de cada destino, y la entrada en la fase de estancamiento puede implicar una corrección brusca.

\section{Bibliografía}

Agarwal, S.

1997 "The resort cycle and seaside tourism: An assessment of its applicability and validity". Tourism Management, 18(2): 65-73.

2002 "Restructuring seaside tourism. The Resort Lifecycle". Annals of Tourism Research, 29(1): 25-55.

Aguiló, E., Barros, V., García, M. A. y Rosselló, J. 2004 Las actitudes de los residentes en Baleares frente al turismo. Turisme i Investigació $\mathrm{n} .^{\circ}$ 7. Palma de Mallorca: Universitat de les Illes Balears.

Akama, J. S.

1999 "The evolution of Tourism in Kenya". Journal of Sustainable Tourism, 7(1): 6-25.

Allen, L. R., Hafer, H. R., Long, P. T. y Perdue, R. R. 1993 "Rural residents' attitudes toward recreation and tourism development". Journal of Travel Research, 32(1): 27-33.

Baker, R. J.

1983 An Analysis of Urban Morphological and Tourist Precincts within Selected Coastal Resort of the Port Stephens, Great Lakes Area, New South Wales. Unpublished master thesis, University of England, New South Wales.

Baum, T.

1998 "Taking the exit route: extending the tourism area life cycle model". Current Issues in Tourism, 1, 167-175.

Benedetto, C. A. y Bojanic, D. C.

1993 “Tourism Area Life Cycle extensions". Annals of Tourism Research, 20(3): 557-570.

Bianchi, R.

1994 "Tourism development and resort dynamics: an alternative approach". Progress in Tourism, Recreation and Hospitality Management, 5(2): 181-193.

Buades, J.

2004 On Brilla el Sol. Turisme a Balears abans del Boom. Eivissa: Res Pública Edicions.

Butler, R. W.

1980 "The concept of a tourist area cycle of evolution: Implications for the management of resources". The Canadian Geographer, 24(1): $5-12$. 
2006a The Tourism Area Life Cycle. Vol. 1. Applications and Modifications. Clevendon: Channel View Publications.

2006b The Tourism Area Life Cycle. Vol. 2. Conceptual and Theoretical Issues. Clevendon: Channel View Publications.

2012 "Mature Tourist Destinations: Can we recapture and retain the magic?" En Vera, J. F. y Rodríguez, I. (eds.). Renovación y reestructuración de destinos turísticos en áreas costeras. Marco de análisis, procesos, instrumentos y realidades (pp. 19-36). València: Publicacions de la Universitata de València.

Cerdà, J. y Rodríguez, R.

1999 La repressió franquista del moviment hippy a Formentera (1968-1970). Eivissa: Res Pública Edicions.

Cirer, J. C.

1998 L'economia d'Eivissa i Formentera en el segle XIX (1782-1900). Palma de Mallorca: Edicions Documenta Balear S.L.

2000 Els moviments de passatgers a l'aeroport d'Eivissa (1964-1999). En Estudis sobre turisme a Eivissa i Formentera (pp.73-95). Eivissa: Editorial Mediterrània-Eivissa.

2001 Evolució de l'oferta de places turístiques a Eivissa i Formentera (1950-2000). En Estudis sobre turisme a Eivissa i Formentera 2 (pp. 73-93). Eivissa: Editorial Mediterrània-Eivissa. 2002 L'economia d'Eivissa i Formentera en el segle XX. Palma de Mallorca: Edicions Documenta Balear S.L.

2004 De la fonda a l'hotel. La Gènesi d'una Economia Turística. Palma de Mallorca: Edicions Documenta Balear S.L.

2009 La invenció del turisme de masses a Malllorca. Palma de Mallorca: Edicions Documenta Balear S.L.

Cooper, C. P.

1990 "The life-cycle concept and tourism". Tourism in the 1990s' Conference (University of Durham, UK).

Cooper, C. P. y Jackson, S.

1989 "Destination life cycle: The isle of Man case study". Annals of Tourism Research, 16 (3): 377-398.

de Castro, F. G.

2003 La isla perdida. Memoria de una época de Ibiza. Eivissa: Editorial Mediterrània-Eivissa.

Debbage, K. G.

1990 "Oligopoly and the resort cycle on the Bahamas". Annals of Tourism Research, 17(4): 513-527.

Diario de Ibiza

2013 Ibiza Tendrá el primer complejo Hard Rock Hotel de Europa.
Fajarnés, E.

1995 Lo que Ibiza me inspiró. Eivissa: Consell Insular d'Eivissa i Formentera.

Federación Hotelera de Ibiza y Formentera (Fehif) 2005 Ibiza. Plan Estratégico de Marketing 2005-2010. Eivissa: Federación Hotelera de Ibiza y Formentera.

Fernando, J. (Coor.), López, F., Marchena, M. J. y Anton, S.

2011 Análisis territorial del turismo y planificación de destinos turísticos. Valencia: Editorial Tirant Lo Blanch.

Foster, D. M. y Murphy, P. E.

1991 "Resort cycle revisited: the retirement connection”. Annals of Tourism Research, 18(4): 553-567.

Gale, T.

2005 "Modernism, post-modernism and the declive of british seaside resorts as long holiday destinations: A case study of Rhyl, North Wales". Tourism Geographies, 7(1): 86-112.

Getz, D.

1992 "Tourism planning and destination life cycle". Annals of Tourism Research, 19(4): 752-770.

1994 "Resident attitudes towards tourism: a longitudinal survey in Spey Valley, Scotland". Tourism Management, 15(4): 247-258.

Haywood, K. M.

1986 "Can the tourist area life cycle be made operational?". Tourism Management, 7(3): 154-167.

Hosteltur

2012 Ushuaïa Ibiza Beach Hotel se ampliará con otro Hotel de 8 plantas.

2013 El Plan de Excelencia de Matutes creará 3.000 empleos.

Hovinen, G. R.

1982 "Visitor cycles. Outlook for tourism in Lancaster County". Annals of Tourism Research, 9(4): 565-583.

2002 "Revisiting the destination lifecycle model". Annals of Tourism Research, 29(1): 209-230.

Ioannides, D.

1992 "Tourism development agents. The cypriot resort cycle". Annals of Tourism Research, 19(4): 711-731.

Lankford, S. V.

1994 "Attitudes and perceptions toward tourism and rural regional development". Journal of Travel Research, 24(3): 35-44.

Méndez, T.

2001 "Prólogo". En Ramón, E., Historia del turismo en Ibiza y Formentera. 1900-2000. Eivissa: Genial Ediciones Culturals, 5-7.

Meyer-Arendt, K. J

1985 "The Grand Isle, Louisiana resort cycle". Annals of Tourism Research, 12(3): 449-465. 
Morgan, M.

1991 "Dressing up to survive: marketing Majorca anew". Tourism Management, 12(1): 15-20.

Oglethorpe, M. K.

1984 "Tourism in Malta: A Crisis of Dependence". Leisure Studies, 3(2): 147-161.

Papatheodorou, A.

2004 "Exploring the evolutions of tourism resorts". Annals of Tourism Research, 31(1): 219-237.

Perdue, R. R., Long, P. T., y Allen, L.

1990 "Resident support for tourism development". Annals of Tourism Research, 17(4): 586-599.

Planells, A.

1984 Ibiza y Formentera, ayer y hoy. Barcelona: Antonio Planells Ferrer.

Planells, M.

1986 Ibiza, la senda de los elefantes, volumen II. Barcelona: Ediciones Obelisco S. A.

2002 El nacimiento de Babel -Ibiza años 60-. Eivissa: José Ferrer y Vicent Guillamó.

Plog, S. C.

1974 "Why destination areas rise and fall in popularity". Cornell Hotel and Restaurant Administration Quarterly, 14(4): 55-58.

Prideaux, B.

1996 "The tourism life-cycle: A beach destination study". En Pizam, A., y Mansfield, Y. (Eds.), Tourism, crime and international security issues. Chichester: Wiley.

2000 "The Resort Development Spectrum (a New Approach to modeling Resort development)". Tourism Management, 21(3): 225-240.

Priestley, G. y Mundet, L.

1998 "The post-stagnation phase of the resort cycle". Annals of Tourism Research, 25(1): 85-111

Pulina, M., Dettori, D. G. y Paba, A.

2006 "Life cycle of agrotouristic firms in Sardinia". Tourism Management, 27(5): 1006-1016.

Ramón, E.

2001 Historia del turismo en Ibiza y Formentera. 1900-2000. Eivissa: Genial Ediciones Culturals.

Richardson, S.

1986 "A Producto Life Cycle Approach to Urban Waterfronts: The Revitalization of Galveston". Coastal Zone Management Journal, 14, 21-46.

Rodríguez, R.

2003 Avantguarda artística $i$ societat a Eivissa (1933-1985). Eivissa: Res Pública Edicions.

Rozenberg, D.

1990 Ibiza, una isla para otra vida: inmigrantes utópicos, turismo y cambio cultural. Madrid: Centro de Investigaciones Sociológicas.

Rubert, X.

1985 "Del Mediterráneo como mito cultural". En Arquitectura y espacio rural en Ibiza. Palma: Colegio de Arquitectos de Baleares.
Russell, R. y Faulkner, B.

2004 "Entrepreneurship, chaos and the tourism areal lifesycle". Annals of Tourism Research, 31(3): 556-579.

Sedmak, G. y Mihalic, T.

2008 "Authenticity in mature seaside resorts". Annals of Tourism Research, 35(4): 1007-1031.

Serra, A.

2002 Marketing turístico. Madrid: Ediciones Pirámide.

Smith, R. A.

1992 "Beach resort evolution: implications for planning". Annals of Tourism Research, 19(2): 304-322.

Soriano, F.

1996 Pequeña historia del turismo en las Baleares. Palma de Mallorca: Bitzoc.

Torres, J.

1961 "Las comunicaciones marítimas con Ibiza". Boletín de la Cámara Oficial de Comercio, Industria y Navegación de Palma de Mallorca n. ${ }^{\circ} 630$.

Vuillier, G.

2000 Les Illes Oblidades. Viatge a Eivissa. Eivissa: Res Pública Edicions.

Weaver, D. B.

1990 "Grand Cayman Island and the Resort Cycle Concept”. Journal of Travel Research, 29(2): 9-15.

Wilkinson, P. F.

1987 "Tourism in small island nations: A fragile dependence”. Leisure Studies, 26(2): 127-146.

\section{Recursos electrónicos}

AENA: http://www.aena.es (Consultado el 30/07/2013) Federación Hotelera de Ibiza y Formentera (Fehif): http://www.fehif.net (Consultado el 30/07/2013) Ibestat: http://ibestat.caib.es (Consultado el 30/07/2013)

INE: http://www.ine.es (Consultado el 31/07/2012) Observatori de Turisme: http://observatoridelturisme.caib.es (Consultado el 30/07/2013)

Recibido:

$11 / 12 / 2012$

Reenviado:

$26 / 04 / 2014$

Aceptado:

$28 / 04 / 2014$

Sometido a evaluación por pares anónimos 